\title{
EL PROBLEMA DE LOS AFECTOS EN LA FORMACIÓN DE LA FAMILIA EN LA NOVELA CHILENA LA HECHIZADA DE FERNANDO SANTIVÁN ${ }^{1}$
}

\author{
THE AFFECTS PROBLEM ON THE FAMILY CONFIGURATION IN THE \\ CHILEAN NOVEL LA HECHIZADA BY FERNANDO SANTIVÁN
}

\author{
Christian Troncoso Castillo \\ Dr. en Literatura Latinoamericana. \\ Grupo de investigación "Literatura y Escuela”, Universidad Autónoma de Chile \\ Chile \\ christian.troncoso@uautonoma.cl
}

\begin{abstract}
Resumen: El objetivo de esta investigación es rastrear cómo los afectos se cuelan en la cultura chilena, tomando como punto de partida una obra instalada en el canon tradicional como La Hechizada. La Hechizada, como texto canónico, es una obra hija de su tiempo en muchos aspectos. El relato se basa en un enamoramiento de juventud, que causa más de algún problema porque los supuestos amantes provienen de castas distintas. Tomando en cuenta el fin pedagógico de las novelas realistas, quizás la perspectiva del autor sea muy contraria a la validación social de los afectos, pero eso no quita que estos sean los que incentivan el desarrollo de las acciones de la historia. La forma en que problematizan las relaciones amorosas a partir de los roles sexuales masculinos y femeninos de principios del siglo XX son un punto de partida para el estudio de los afectos en la literatura chilena. Adquiere relevancia examinar la literatura como testigo privilegiado de las transformaciones sociales, aunque este desafío supone una tarea de mayor envergadura que las líneas del presente artículo.
\end{abstract}

Palabras clave: Afectos, familia, mujer, campo, literatura chilena.

Abstract: The objective of this research is tracking how the affections appears into Chilean culture, taking as a point of departure a literary work installed in the traditional canon like La Hechizada. La Hechizada, as a canonical text, is a work child of her time in many aspects. The narration is based on a crush on youth, which causes more of a problem because the supposed lovers come from different castes. Taking

${ }^{1}$ Este artículo es resultado del Proyecto de Investigación DIUA 167-2019, financiado por la Universidad Autónoma de Chile. 
into consideration the pedagogical purpose of realist novels, perhaps the author's perspective is very opposite to the social validation of affections, but it does not mean that the affections are the engine of the development of the actions in the story. The way in which love relationships are problematized from the male and female sexual roles of the early twentieth century are a starting point for the study of affections in Chilean literature. It is relevant to examine the literature as a privileged witness of social transformations, although this results in a challenge that crosses this article, but which is a larger task.

Keywords: Affections, family, women, countryside, Chilean literature.

Recibido: 11/03/2020. Aceptado: 11/10/2020.

\section{Introducción}

T a Hechizada de Santiván fue publicada en 1916 y recibió elogiosos coVaisse, Iris y Alone, entre otros, escribieron sobre esta novela como una obra maestra, acentuando, casi siempre, aspectos miméticos de las descripciones de tipos humanos, paisajes y conflictos. Sin embargo, fue poca la investigación en torno a los procedimientos retóricos que configuran la historia, quizás solo Ricardo Latcham, años más tarde, fijó su atención en que esta obra "es un acierto de técnica, de frescura narrativa, de gracia en el relato" (Latcham, 1948); el crítico distingue, en el estilo del autor, la utilización de la nostalgia del recuerdo como elemento de verosimilitud mucho más prístino que el de los naturalistas coetáneos, pues la escritura de Santiván conjuga - para Latcham- los estilos romántico y realista, aunque, también es cierto, como dice Gotschlich (2001), que La Hechizada "se aleja del tipo de narración documental que recorre buena parte del realismo hispanoamericano" (pp. 106-107), por esta razón es que tanto Gotschlich como Goic clasifican esta novela -y al autor- como mundonovista, en tanto, otros como Latcham y Ferrero entienden a Santiván dentro de los precursores criollistas. Por su parte, Oelker y Muñoz (2014) destacan el rol de la Colonia Tolstoyana que influyó a varios autores desde su idealización o desde su polémica.

Con todo, tanto el autor como la obra se ubican en la tradición literaria del realismo que, a pesar de sus temáticas sociales, está vinculada a la burguesía, lo que se hace visible en el modo en que se aborda a los sujetos 
anormales en la obra. En este sentido, la novela tiene un fin pedagógico de momento que castiga todo aquello que no es útil ni dócil para un sistema capitalista que privilegia los espacios de producción económica. En este trabajo se problematizará sobre el modo en el que en el universo narrado de La Hechizada se margina las formas de masculinidad divergentes y las uniones entre clases distintas, en el entendido de que estas se gestan a través de los afectos que son los que polemizan en la formación de una pareja frente a una estructura social tradicional que, finalmente, se impone.

En la actualidad, el concepto de familia se ha diversificado, considerando uniones tradicionalmente no oficiales, como familias homoparentales, madres solteras con hijos, padres solteros con hijos, o la inclusión de las mascotas como parte del núcleo familiar. Progresivamente, este tipo de familia se ha ido incorporando a la institucionalidad y, en este contexto, es un ejercicio crítico reexaminar el canon literario, relevando temas que hasta ahora no habían sido tratados por no formar parte de una oficialidad política.

Respecto del caso específico de La Hechizada, conviene situar su publicación en una coyuntura histórica en la que los matrimonios convenidos tenían, hace poco, una connotación pública de relevancia, pues lo tradicional todavía eran los matrimonios convenidos entre las familias de los cónyuges. Las perspectivas de lectura en este trabajo se realizarán con la intención de analizar el modo en que las uniones de pareja -y a partir de ello, las familias- pasaron de ser convenidas y realizarse producto del afecto. De hecho, en la primera ley de matrimonios chilena, de 1844, se reconocen todavía los matrimonios arreglados con las mismas garantías y beneficios que los matrimonios celebrados "a pedimento de las partes" (Ley sobre Matrimonios, art. 2). Las perspectivas teóricas que guiarán la lectura vendrán de la teoría de los afectos, que desde principios de este siglo ha permitido dar un giro investigativo en las ciencias sociales a fenómenos cotidianos muy complejos.

\section{El afecto en el núcleo familiar}

El "giro afectivo" como orientación interdisciplinar ha permitido descubrir el modo en que el poder ha hecho presa a los sujetos y cómo las sociedades 
de control capturan el cuerpo a través de los afectos, pues, progresivamente:

These politic, economic, and cultural transformations pressure a shift in capitalist accumulation to the domain of affect or preindividual bodily capacities-to life itself. That is to say, there is a putting into play something like a primitive accumulation for the reorganization of value around bodily capacities. (Clough, 2007, p.21)

Las políticas sobre el afecto llevaron, en un primer momento, a normar las uniones matrimoniales consensuadas en función de la reproducción y el trabajo, aunque también del tributo y el control de los dispositivos estatales como garantes del orden. Así se cometieron grandes formas de violencia contra la mujer, amparadas por la iglesia, en las jóvenes repúblicas latinoamericanas, a través de la obligatoriedad del matrimonio para las parejas de hecho (Jelin, 2016). Parejas, obviamente, heterosexuales y monógamas, pues eran las que aseguraban la producción económica sostenida del sistema capitalista.

Quedaron en la trastienda de los estados latinoamericanos todos los afectos no útiles e indóciles por lo que la configuración de relaciones sociales a través de los afectos pudo volverse, incluso, subversiva. Es inevitable pensar que, en esas relaciones sociales, el deseo actúa como amalgama, entre otras razones, porque los márgenes entre deseo y afecto son difusos desde la concepción misma de afecto de Spinoza que revisara Deleuze. El estudio del afecto puede ayudar a problematizar ciertas formas discursivas y/o poéticas hegemónicas, así lo entiende Mabel Moraña (2012):

El "giro afectivo" propone más bien una liberación de la instancia representacional y un estudio del afecto como forma desterritorializada, fluctuante e impersonal de energía que circula a través de lo social sin someterse a normas ni reconocer fronteras. Afecto nombra así un impulso que, como el de la sexualidad estudiado por Freud y reenfocado por Foucault, permite la problematización de las formas de conocimiento y de las conductas sociales así como de los procesos de institucionalización del poder y sus asentamientos (inter)subjetivos. (p. 322)

El flujo de emociones que supone el afecto es plausible de estudio en esa forma rizomática de operar. La mención Freud y Foucault no es arbitraria, al fin y al cabo, una aproximación a los afectos es un estudio sobre el deseo 
y el poder. Como propone Moraña, el “giro afectivo” supone también el estudio de otras formas de conocimiento, lo que nos llevará, en el estudio literario, a la búsqueda de otras epistemologías a través de diversas formas de representación (como la performance, por ejemplo). En ese sentido, cabe la necesidad de rastrear también estas formas de conocimiento disruptivas en la literatura chilena, especialmente, en aquellos textos que vienen de una tradición burguesa.

\section{Baltasar y los afectos}

Cuando Latcham refiere la prolijidad técnica de Santiván en La Hechizada está enfatizando el modo en que el autor aborda las descripciones, que, a juicio del crítico: "no se pierde en divagaciones, no mira al paisaje sino cuando éste es útil para marco indispensable de los protagonistas" (Latcham, 1948). Como afirma Garrido (1996), el espacio narrativo suele funcionar como metáfora de los personajes que circunda. De allí que la importancia del paisaje no solo tenga una relevancia extraliteraria y mimética, sino que contribuye a la descripción del conflicto narrado.

Como ejemplo del genio creativo, Latcham expone la escena de la batalla final entre Baltasar y Saúl, y el posterior desenlace de la obra, como una pieza de "maestría clásica". Desde el punto de vista del espacio narrado, la escena establece dos opuestos en el mismo cuadro -civilización y barbarie-, lo que justamente es una forma de la estética romántica: "Era hábil jinete el campeón campesino; pero el otro había servido su guardia en un regimiento de caballería y, en buen caballo, se sentía invencible" (Santiván, 1916, p. 101). En esta escena, es claro el modo en que la lucha entre los jinetes es una lucha ciudad/campo, o mejor, una lucha civilización/barbarie; a pesar de que gana la gresca el jinete citadino, lo urbano no logra imponerse por sobre lo rural, pues el motivo de la batalla -la posesión de Humildeno se concreta por parte de Baltasar.

El fragmento de la obra referido por Latcham enfatiza la pureza, pero también la ingenuidad de Baltasar al pensar que puede subvertir el orden social casándose con una campesina. Simbólicamente, esto se encuentra en torno a las descripciones relacionadas con lo blanco, que marcan el "equilibrio final" del relato: 
Se levantó cuanto apenas empezaba la mañana a aclarar, y se dirigió a los corrales de la lechería.

Sediento de algo puro que le redimiera de la fiebre mental que lo convulsionaba, bebió con supersticiosa fruición un vaso de leche esprimido de las ubres de una vaca blanca.

Los campos surgían de la sutil neblina de la tierra con una inocente castidad de virgen que nace a la vida, el rostro maravillado y el alma en blanco (pp. 107-108)

Nótese el modo en que, incluso, la complejidad gramatical de las estructuras que señalan el blanco se va complejizando a medida que avanzan las descripciones; así también lo hacen aquellos conceptos abstractos en relación con el blanco. En el fondo, el espacio que alberga a Baltasar es una metáfora de la inocencia del protagonista, quien creyó que podría revocar las leyes de la naturaleza profetizadas por su tía. Como todo texto criollista, en la novela existe un hado maligno que es imposible que el protagonista rompa, y que el personaje de la tía Dolores anuncia desde el principio del relato: “iAh! Decía tía Lolo, sonriendo con benevolencia, tu carácter se parece mucho al de un pariente nuestro que murió de manera trágica. Era tan loco como tú, y bueno como el pan. Pero lo perdió su fantasía” (Santiván, 1916, pp. 10-11) y sentencia: “iTú no eres como todos, hijo mío, y por eso tendrás que sufrir mucho! / ¿tendrá razón la tía Lolo?” (p. 12). La pregunta del narrador supone ya la sentencia de Baltasar. Las palabras "loco" y "fantasía" también tienen en estos fragmentos ecos de los sentidos que Foucault y Freud les otorgan respectivamente: Baltasar es marcado como un anormal, aunque el afán civilizador del protagonista y el modo en que asume su función de poder no dista de otros personajes en textos de tradición machista. La "hamartia" que desencadena la acción narrativa no está en querer poseer a Humilde, pues nos queda claro el modo cosificado en que la mujer es tratada como uno más de los bienes muebles:

¿I cómo estamos de chiquillas, Juan Ramón?

El campesino se lleva la mano con lentitud al ralo bigotillo, y mira con perezosa actitud las lontananzas lejanas. Luego responde el mocetón:

-Malito, señor malito... Las «torcazas» se fueron para «Las cruces», y la Domitila del «Pelao» está en el pueblo.

(...) 
-iPuros bagres, don Baltasarito! Para encontrar buen ganado, habría que remontarse hasta las posesiones de don Tobías, al otro lado del estero... (p. 18)

Como se ve, la normalización de la violencia sexual contra la mujer y la objetivación que se hace de ellas como producto transable aplica para las campesinas, a quienes se les caracteriza, cual siervas de la gleba, indisociadas del lugar al que pertenecen. La utilización sexual de las mujeres del campo por parte del patrón es una forma de violencia de larga data y sobre la cual se ha escrito mucho; a menudo también se justificaba esos comportamientos en tanto se llevaban en el ámbito privado y no constituían un atentado serio contra la estructura jerárquica, de hecho, era una manifestación del poder del hacendado. Sin embargo, la razón por la que Baltasar es castigado radica en el intento por subvertir el orden de clases. Tal como lo reconoce su abuela:

Las locuras de Juventud yo las comprendo. Son las válvulas de escape de la sangre moza que bulle en las venas (...) Tu carácter es sensible y vehemente. Los detalles más pequeños dejan en tu espíritu una huella profunda, y lo que hoy te produce la felicidad, mañana te produciría el desastre. Mira, hijo... Las leyes del Destino, las leyes dictadas por los hábitos a través de muchas generaciones, no se pueden quebrantar impunemente. Esa niña, tan buena y tan bella, no podrá ser jamás tu esposa (...) porque tú y ella habéis crecido y os habéis educado en muy distintas esferas (pp. 104-105).

El fragmento es muy ilustrativo. No solo por lo gráfico de las metáforas sexuales: válvula de escape y sangre que bulle; sino por lo directo del problema de carácter de Baltasar que desencadena la acción principal del relato. La utilización de la mayúscula en "Destino” y su grado de importancia, hacen pensar en el ananke griego, que es inevitable para todos. De hecho, la estructura del relato gira en torno a los elementos de la tragedia griega al estilo aristotélico. El énfasis en que los roles y jerarquías sociales aristocráticas y machistas se mantengan aclara qué es lo que hace diferente a Baltasar: quiere casarse con una mujer inferior, aun cuando solo la sola posesión sexual informal de ella bastaría para aplacar sus deseos. En el fondo, en el texto se hace la advertencia sobre lo subversivo que es el matrimonio 
consensuado (o por afectos), basados en la diferencia de clases, pero, sobre todo, en los modos de conocimientos disímiles, que harían ininteligibles ambas visiones de mundo entre sí. En este sentido, la tía Lolo, personaje que representa al poder disciplinario y que funciona como un profeta del poder, ha notado el modo en que Baltasar es afectado por ciertos detalles: "los detalles más pequeños dejan en tu espíritu una huella profunda", aquellos no son los que configuran una política, como lo entiende Foucault, sino que una erótica, al estilo romántico o modernista. Los detalles a los que se refiere la anciana no son otra cosa sino aquella corporalidad que al adolescente le despierta Humilde. En términos de Deleuze, los detalles corresponden a la experiencia háptica de Baltasar con Humilde.

\section{El elemento ctónico como catalizador de las pasiones}

Como en otros textos naturalistas, la naturaleza, entendida como el paisaje rural de la provincia, despierta pulsiones sexuales en los personajes; es más, la propia naturaleza parece actuar como un personaje incidiendo a través de su influjo sensual en la trama. Subercaseaux identificaba este aspecto en términos más generales, como una forma de energía espiritual: "En La hechizada (1916), de Fernando Santiván, los campos son fuente de energía espiritual; refiriéndose al 'verde follaje de los mañíos', el narrador dice que son 'como lanzas araucanas"' (Subercaseaux, 2007, p. 18).

En concreto, en las novelas naturalistas y especialmente, en nuestro caso, en La Hechizada, el campo es un catalizador de los afectos, lo cual es subversivo en tanto desborda los límites que le ha puesto el poder disciplinario. En la primera conversación que Humilde y Baltasar tienen en la huerta se expresa claramente este aspecto:

Ahora, a las rosas, se mezclan los jazmines; de vez en cuando, el rústico olor de la yerba buena y del toronjil vence a los otros perfumes, y evocan la vida sana del campo libre.

Baltasar siente abrasadas las espaldas bajo el sol; la sangre se agolpa a sus mejillas, y una embriaguez de salud le hace concebir la vida en ese momento como una enorme crepitación en que se confunden los sonidos con los perfumes, y estos con la visión deslumbrante del cielo, cruzado de pedrerías y saetas de oro. (Santiván, 1916, p. 101) 
Recordemos lo que Deleuze y Guattari sostienen sobre lo háptico: "Háptico es mejor término que táctil, puesto que no opone dos órganos de los sentidos, sino que deja entrever que el propio ojo puede tener esa función que no es óptica" (2002, p. 499) y agregan: "Es una animalidad que no se puede ver sin tocarla espiritualmente, sin que el espíritu no devenga un dedo, incluso a través del ojo" (p. 500). Nótese como, en el fragmento de la obra de Santiván, los olores de la arboleda producen una excitación sensual que el narrador explica con una sinestesia, tal como lo describen Deleuze y Guattari. Estos espacios son explícitamente eróticos:

En un espacio circular rodeado de troncos cubiertos por enredaderas y pequeños arbustos, en un sitio en que las ramas de los árboles formaban una bóveda más espesa que en otras partes, bajo la verde claridad que prestaba misterio al ambiente, había una depresión del terreno. Apartando los helechos que lo rodeaban, aparecía el agua cristalina, como un espejo oculto y limpio, que parecía mirar hacia lo alto con una mirada de místico embeleso. (...)

Más de un idilio campesino floreció en la perfumada alfombra de violetas silvestres que rodeaban la fuente, y más de una vez se unieron dos labios sedientos en un beso, no menos dulce que el agua de la solitaria vertiente. (Santiván, 1916, pp. 72-73).

Los espacios y ambientes del campo son catalizadores de los afectos, pues despiertan, a través del aroma y el tacto, una sensualidad que despierta el deseo sexual. En toda la literatura occidental este tipo de situaciones se narra en una especie de "arquetipo de la fuente", en el que las ninfas entregan su revelación: grandes arboledas con frondosos arbustos son descritos en la literatura como espacios concéntricos, en cuyo núcleo hay siempre una fuente de agua corriente hacia donde se dirigen los amantes. Los olores, colores y texturas se van haciendo más visibles a medida que se avanza y la fuente representa la experiencia mística de la revelación. Esto, obviamente, afecta la sensibilidad de los personajes y se pone la atención de las descripciones sobre pequeños detalles eróticos que afectan las sensibilidades en el relato, comenzando por el narrador. En ese sentido, La Hechizada sigue una forma tradicional de representación del campo que, como epítome de la fertilidad, es escenario de toda sensualidad: "El aroma de los campos parecía exhalarse por todos los poros de la tierra y de 
las plantas, como una muda ofrenda de voluptuosidad exuberante" (p. 70). Todas las figuraciones de los elementos ctónicos en la novela están determinadas por la fertilidad en las descripciones.

\section{La representación de la mujer}

El narrador es claro que no es Humilde quien posea rasgos físicos provocadores, es Baltasar quien, condicionado por el campo, experimenta este delirio háptico:

El joven sentíase poseído por indefinible embriaguez. Buscaba los ojos de Humilde para depositar en ellos el fluido de pasión que comenzaba a florecer en su alma. Sentía que las lágrimas se agolpaban a los ojos, sin motivo; no sabía si de alegría, de agradecimiento o de dolor. La tristeza del atardecer penetraba a su corazón con violencia lacerante y lo llenaba de místico arrobamiento. Hubiera deseado arrodillarse y murmurar no se sabe qué oración férvida y candorosa. (p. 47)

Las descripciones en torno al deseo de Baltasar abundan en metáforas sexuales que se mezclan con un lenguaje religioso, de a poco, se produce una vivencia mística-sexual. Baltasar está poseído por su deseo. Esta forma de la experiencia sensual ha sido descrita por Roberto Calasso como "la locura que viene de las ninfas" (2008). Calasso analiza la figura de la ninfa en la mitología y literatura occidental, vinculándolas directamente con la mente de los hombres. Registra en su libro que la de las ninfas es la única posesión feliz porque es el éxtasis sexual. Sin embargo, según él, existen dos tipos de ninfas: por una parte, están aquellas de la posesión feliz, como por ejemplo la ninfa Egeria quien dicta las primeras leyes de Roma al rey Numa Pompilio, por otra parte, están las ninfas cazadoras de cabezas, como Jezabel o Salomé, que llevan a sus cautivos a la destrucción. Esta forma es bajo la que Humilde posee la mente de Baltasar: "Porque estaba loco... era verdad; Humilde se había apoderado de todos sus pensamientos, y ya no podía ver las cosas que lo rodeaban sin enlazarlas en la mente con la suave imagen de ella” (Santiván, 1916, p. 60). Baltasar reconoce esa forma de subyugación por parte de Humilde: “¿Por qué va a ser imposible? iPero si ya la adoro, y apenas la he conocido en esta mañana! Mi vida entera la 
colocaré a tus pies, y nada podrá impedirme que sea tu esclavo” (p. 50). Humilde es una ninfa y la trama girará en torno a su revelación: "su figura, vestida de blanco, adquirió en la penumbra una diafanidad misteriosa. Una ninfa del bosque no tuviera para Baltasar el encanto de la joven avanzando como fascinada por la mullida alfombra de yerbas verdes" (p. 73), la posesión nínfica que experimenta Baltasar comienza abiertamente a ocupar sus pensamientos, sus sentimientos y sus decisiones.

El carácter misterioso sobre el cual se describe a Humilde le otorga naturaleza ambigua, por un lado, es descrita como un ser angelical en un territorio lóbrego, por otro lado, como un ser demoniaco. Baltasar confiesa que "iNo sabía decir si era un ángel o un demonio quien me ha robado el alma!” (p. 86). Más adelante, el narrador se refiere a Humilde como "un aspecto de ser vampirizado" (p. 72), esa figura está abiertamente relacionada con el personaje de Saúl: "bastaría aquella tarde de alejamiento y de intimidad para arrancarla de las garras de una sombra vampiresca” (p. 78). Es decir, lo demoniaco y vampiresco de Humilde reside en su cercanía a su primo Saúl. Sin embargo, este statu quo respecto de lo que la naturaleza de la propia Humilde es lo que desarrolla la tensión dramática en la obra. Esta se instala desde el principio en las voces siempre ininteligibles del rumor:

- No sería raro que tuviera razón, su mercé... Pero creo que... Vamos, es un pensar... Estas palomitas tiernas suelen esconder garritas de águila... - Concluye...

- Pa mí que la señorita Humilde tiene su embuchadita... Así dicen las malas lenguas (p. 23).

Suazo (2018) identifica estas formas de representación de la mujer como modos de cristalización de un miedo hacia el sexo femenino, que en la tradición occidental ha llevado también a crear una imagen de apariencia angelical, pero de espíritu demoniaco: "el miedo a la mujer-monstruo funciona de manera similar: se nos presenta como una perturbación del 'orden natural'” (p. 127). De allí que se presenta una forma especie de epistemología femenina en la experiencia háptica, la cual, en el relato, produce efectos adversos en los hombres al ser poseídos por las mujeres.

La relación de un modo de conocimiento eminentemente háptico asociado a la mujer y un conocimiento óptico asociado a los hombres es una oposición que, por fuerza, responde a una visión hija de su tiempo, en la 
que las mujeres representaban tanto el anhelo más sublime como los más oscuros deseos. En todo caso, la oposición no es simple, sino que se entrecruzan también los ejes de lo bueno y lo malo vinculado a lo urbano y lo rural. Es así como tenemos lo óptico/háptico, lo bueno/malo y lo urbano/rural (que es otra forma de civilización/barbarie, una lógica de castas) como ejes constitutivos del relato que organizan el espacio narrativo y condicionan las acciones de personajes. En otras palabras, por ejemplo, para la visión tradicional, representada por la tía Lolo, lo háptico es una forma de perdición porque hace que los hombres urbanos se relacionen emocionalmente con mujeres rurales; hay que poner atención que, en el pasaje citado unas líneas atrás, lo que para ella es problemático no es que Baltasar se sienta sexualmente atraído por Humilde, sino que la quiera hacer su esposa. Es decir, hay una validación del dominio del hombre urbano sobre la mujer rural como objeto, lo que resulta incomprensible, en esa lógica, es que esa relación tenga que ser reconocida oficialmente por la sociedad.

Otro tema que aborda el último fragmento citado y se proyecta a lo largo de la narración es la comparación que se establece entre Humilde y las aves, la que luego alcanza también a Saúl y a Baltasar. La paloma identifica en muchas ocasiones al personaje de Humilde, así como el gavilán identifica a Saúl: "Aquel primo era el gavilán que pudo fascinar a la avecilla con sus duros ojos” (Santiván, 1916, p. 78). En este contexto, se explica la problemática de la novela y la metáfora de las aves para describir la relación entre Humilde, Saúl y Baltasar es explicada mediante una analogía, de allí se extrae el fin pedagógico de toda novela realista:

Pero los disturbios más sangrientos se producen entre las crías nuevas y las antiguas parejas, cuando los recién llegados al mundo pretenden establecer casa aparte o suplantar en el propio hogar a sus progenitores. El egoísmo parece no ser cualidad exclusiva de los hombres. (p. 38)

Explicar el triángulo amoroso entre Humilde, Baltasar y Saúl no es simple. Primero, porque nunca se sabe si, efectivamente, Humilde estaba interesada en Baltasar o si, finalmente, se somete al orden social que le corresponde y acepta su destino con Saúl. Lo que sí es verificable, es que el problema se produce por el interés de "formar casa aparte", que según la explicación analógica citada sería motivada por el egoísmo. 


\section{Conclusiones}

Al analizar la obra en sus dinámicas internas, queda fuera la atención a quién escribe la obra. En este caso, es un sujeto masculino adscrito a la tradición. En la obra se castiga los afectos -incluso cuando estos aún tienen el sesgo machista- porque resulta subversiva la validación de estos ante la sociedad. No hay que olvidar que, en el contexto de producción de la obra, el matrimonio era también una marca de clase, puesto que solo las clases acomodadas podían pagar los gastos que esto involucraba. Además, hay que tomar en cuenta que el concubinato en la práctica resultaba en mayor independencia para las mujeres porque no entregaba su patria potestad al hombre, en cambio, el matrimonio suponía una entrega legal de la mujer como bien a su marido. En La Hechizada, el problema que motiva el desarrollo de la acción es, justamente, el de la validación de un afecto ante el poder central, sea este la iglesia o el Estado. En el texto se muestra como causa de esto a la distinta masculinidad de Baltasar, pues es un personaje que se deja llevar por la pasión en vez de la racionalidad machista de clase aristocrática.

Es claro que la perspectiva de Santiván es tradicional, sin embargo, desde el punto de vista de la temática que instala, La Hechizada es un punto de partida a la hora de analizar la historia de los afectos en la literatura chilena, toda vez que, a través de esto, puede visibilizarse el modo en que ha resultado posible una emancipación de la mujer y cómo la literatura ha sido testigo directo e indirecto de estas transformaciones.

\section{Referencias bibliográficas}

Calasso, R. (2008). La locura que viene de las ninfas. Madrid: Sexto Piso. Clough, P. (2007). The affective turn: theorizing the social. Columbia: Duke University Press.

Deleuze, G. y Guattari, F. (2002). Mil mesetas: capitalismo y esquizofrenia. Valencia: Pretextos.

Garrido, A. (1996). El texto narrativo. Madrid: Síntesis.

Gotschlich, G. (2001). El realismo artístico de La Hechizada de Fernando Santiván, Anales de literatura chilena (2), pp. 103-119. 
Jelin, E. (2016). Pan y afectos. La transformación de las familias. Buenos Aires: Fondo de cultura.

Latcham, R. (17 de octubre de 1948). La Hechizada y palpitaciones de vida [artículo] Ricardo A. Latcham. La Nación (Santiago, Chile). Archivo de Referencias Críticas. Disponible en Biblioteca Nacional Digital de Chile http://www.bibliotecanacionaldigital.gob.cl/bnd/628/w3-article-353497.html . Accedido en 6/2/2020.

Moraña, M. (2012). Postscríptum. El afecto en la caja de herramientas, $E l$ lenguaje de las emociones. Afecto y cultura en América Latina (Moraña, M. y Sánchez, I. eds.). Madrid: Iberoamericana.

Oelker, D. y Muñoz, L. (2014). Diccionario de movimientos y grupos literarios chilenos. Concepción: Editorial Universidad de Concepción.

Subercaseaux. B. (2007). Literatura, nación y nacionalismo, Revista chilena de literatura (70), pp. 5-37.

Suazo, R. (2018). Víboras, putas, brujas: Una historia de la demonización de la mujer desde Eva hasta la Quintrala. Santiago: Planeta. 